\title{
PENINGKATAN KAPASITAS BUMDES DALAM PENYUSUNAN BUSINESS PLAN BAGI PENGELOLAAN KAWASAN EKOWISATA HUTAN BERKELANJUTAN DI DESA SESAOT KECAMATAN NARMADA KABUPATEN LOMBOK BARAT
}

\author{
Addinul Yakin*), Sukardi, Amiruddin, dan Halimatus Sa'diyah \\ Fakultas Pertanian Universitas Mataram \\ ${ }^{*}$ Korespondensi: addinul_yakin@unram.ac.id
}

Diterima 18 November 2018 / Disetujui 27 Desember 2018

\begin{abstract}
ABSTRAK
Dalam rangka melibatkan masyarakat desa dalam pengembangan ekonomi dan pemberdayaan masyarakat, Pemerintah Republik Indonesia melalui Peraturan Menteri Desa, Pembangunan Daerah Tertinggal, dan Transmigrasi Republik Indonesia Nomor 4 Tahun 2015 tentang Pendirian, Pengurusan dan Pengelolaan, dan Pembubaran Badan Usaha Milik Desa (BUMDes). Dalam beberapa tahun terakhir, BUMDes Sesaot sudah mengelola ekowisata Sesaot tetapi belum optimal antara lain karena belum memiliki business plan yang memungkinkan BUMDes untuk memaksimalkan peluang keberhasilan dari pengelolaan ekowisata berkelanjutan ke depan. Dengan adanya business plan tersebut sekaligus juga sebagai alat untuk bekerja sama dengan pihak ketiga dalam hal pendanaan, pembinaan, dam pengembangannya agar usaha yang dijalankan dengan kelayakan ekonomi, sosial dan lingkungan. Melalui program pengabdian pada masyarakat kapasitas BUMDES dan stakeholders dalam penyusunan business plan ditingkatkan melalui penyuluhan dan fasilitasi. Kegiatan pengabdian ini telah dilaksanakan di desa Sesaot Kecamatan Narmada Kabupaten Lombok Barat dengan melibatkan 31 orang partisipan yang terdiri dari pengelola BUMDes serta pelaku usaha lain, serta instansi/lembaga lain yang terlibat dalam pengelolaan kawasan ekowisata serta petani pesanggem yang ikut memanfaatkan kawasan hutan sekitar. Pelaksanaan kegiatan melalui tahap-tahap persiapan, koordinasi dengan BUMDes dan pihat terkait di lapangan, sosialisasi dan penyuluhan, serta fasilitasi penyusunan, dan evaluasi kegiatan sehingga mampu meningkatkan pengetahuan dan ketrampilan peserta tentang teknik penyusunan business plan, serta menghasilkan draft business plan pengelolaan kawasan ekowisata Sesaot oleh BUMDes Desa Sesaot Kecamatan Narmada, Kabupaten Lombok Barat.
\end{abstract}

Kata kunci: Business plan, Sesaot, BUMDes, ekowisata

\section{PENDAHULUAN}

Hutan merupakan sumber daya alam yang sangat bermanfaat bagi kehidupan manusia baik secara ekonomi, sosial, maupun ekologi (Yakin, 2011, 2015) sehingga merupakan bagian yang tidak dapat dipisahkan dari masyarakat sekitar hutan. Untuk itu, kebijakan 
kehutanan harus benar-benar ditujukan untuk memberikan kesejahteraan bagi masyarakat, yang bertumpu pada kebutuhan ekonomi masyarakat sekitar hutan antara lain dengan cara memperluas akses masyarakat atas hutan (Hasan dan Yumantoko, 2016). Kehutanan melalui fungsi hutan sebagai penyangga sistem kehidupan antara lain adalah: hutan sebagai pengatur tata air, hutan sebagai pengatur iklim mikro dan penyerap karbon, dan hutan sebagai sumber plasma nutfah. Peran hutan sebagai penyangga kehidupan (sosial,ekonomi, dan lingkungan) ini sangat penting, sehingga pengelolaannya dilakukan dengan cermat. Selain itu, pengelolaan juga mempertimbangkan berbagai faktor agar dapat terus menjamin keberlanjutan sistem kehidupan tersebut (Dephut, 2009, Yakin dan Othman, 2003, Yakin, 2015, Yakin, dkk., 2016).

Hutan lindung Sesaot adalah wisata hutan yang terdapat Desa Sesaot, sekitar $5 \mathrm{~km}$ sebelah Utara SuranadiKecamatan Narmada Lombok Barat, Nusa Tenggara Barat. Kondisi hutan yang masih sangat alami dengan sumber mata air alami sehingga udara sejuk dengan panorama dan nuansa alam yang khas. Kawasan hutan lindung Sesaot mempunyai luas sekitar 5.999,2 hektar yang 57 persen merupakan hutan alami dan sisanya (43 persen) merupakan hutan buatan. Seluas 5.935 hektar merupakan hutan lindung dan sisanya (64,2 hektar) termasuk hutan kawasan wisata. Di tengah-tengah Sesaot terdapat sungai Aiq Nyet dengan batu kali yang besar-besar dengan 56 sumber mata air yang bermuara di kali Sesaot bahkan dianggap sebagai salah satu sungai suci di Lombok karena airnya berasal dari Gunung Rinjani yang menjadi tempat bermukimnya para dewa.

Secara umum, hutan ini dibagi menjadi 3 area yakni hutan primer, sekunder, perkebunan Mahoni dan Agroforestri. Agroforestri dikembangkan oleh masyarakat dari lahan alang-alang dan hutan sekunder bekas tebangan yang ditinggalkan oleh perusahaan pengelola pada tahun 1976. Sebagai salah obyek ekowisata, sekitar lokasi hutan lindung Sesaot bisa didirikan kemah untuk wisata outbound. Pada awal Pebruari 2018 Masyarakat Desa Sesaot, Kecamatan Narmada menumbuhkan potensi wisata baru dengan menyulap lahan yang berlokasi di pintu masuk Desa Sesaot menjadi taman wisata yang dinamakan Taman Miring (Tamrin), yang dilengkapi beberapa gazebo (berugaq) untuk bersantai dan memiliki spot foto, untuk memperkokoh sebagai destinasi wisata yang berkelanjutan. Kini Desa Sesaot bersama Desa Pakuan dan Buwun Sejati merupakan kawasan destinasi wisata yang berkelanjutan sehingga diperlukan inovasi dan berkreasi dalam penataannya.Selain itu, Dinas Pariwisata Propinsi NTB ingin menjadikan desa Sesaot sebagai "Kampung kreatif" sebagai upaya untuk menata kawasan wisata, mendorong tumbuhnya usaha kecil menengah (UKM) melalui kreativitas, inovasi dan usaha di masyarakat, khususnya yang tinggal di kawasan desa wisata.

Kenyataannya, seringkali kegiatan pengelolaan hutan lebih berorientasi pada pemanfaatan ekonomi dan memarginalkan masyarakat yang hidup di dalam dan sekitar hutan. Konsep trickledown effect yang dijalankan pemerintah dalam pembangunan tidak serta merta meningkatkan kesejahteraan masyarakat secara keseluruhan(Qodriyatun, 2013). 
Oleh karena itu, pengembangan ekonomi lokal dan masyarakat sekitar hutan melalui program pemberdayaan antara lain melalui kerjasama dengan pihak-pihak lembaga swadaya masyarakat (LSM) ataupun kelompok swadaya masyarakat (KSM) harus dikembangkan karena selama ini kurangnya pelibatan masyarakat dalam proses penyusunan dan pengambilan keputusan sehingga belum mampu menurunkan tingkat ketergantungan masyarakat terhadap hutan (Rositah, 2005). Selain itu, pembuat kebijakan cenderung memprioritaskan keuntungan ekonomi jangka pendek dengan mengorbankan hutan alam (Wollenberg, dkk., 2004).

Dalam rangka melibatkan masyarakat Desa dalam pengembangan ekonomi dan pemberdayaan masyarakat, Pemerintah Republik Indonesia melalui Peraturan Menteri Desa, Pembangunan Daerah Tertinggal, dan Transmigrasi Republik Indonesia Nomor 4 Tahun 2015 tentang Pendirian, Pengurusan dan Pengelolaan, dan Pembubaran Badan Usaha Milik Desa (BUMDes). BUMDes ini dapat melakukan beragam usaha seperti pelayanan sosial yang tidak semata-mata orientasi keuntungan seperti Usaha air minum desa baik pengelolaan air bersih maupun pengelolaan air minum (suling), usaha listrik desa, lumbung pangan, dll, melaksanakan jasa keuangan mikro desa, penyewaan ALSINTAN, Lembaga perantara Pemasaran hasil atau produk dan jasa pembayaran, usaha perdagangan, bahkan menjadi kontraktor untuk pembangunan infrastruktur desa. Melalui berbagai unit usaha ini, berbagai kebutuhan dasar warga desa diharapkan dapat diwadahi dan dipenuhi. BUMDEs Desa Sesaot ikut mengembangkan Eko Wisata Sesaot sebagai salah satu usaha pengembangan ekonomi Masyarakat.

Sejauh ini, pengelola BUMDes dan Stakeholders di kawasan tersebut belum memiliki business plan bagaimana agar penataan dan pengembangan kawasan bisa dilaksanakan secara berkelanjutan. Oleh karena itu, penting bagi pengelola BUMDes dan stakeholders terkait untuk memiliki pengetahuan dan pemahaman yang baik dan benar dalam menyusun business plan. Dengan adanya Perencanaan bisnis (bussiness plan) yang jelas dan terukur yang menjadi pedoman sekaligus sebagai alat untuk menjalin kerjasama yang konstruktif dan saling menguntungkan dengan pihak lain baik pemerintah, perbankan/lembaga keuangan, investor, dan sebagainya agar dapat mewujudkan usaha mandiri dalam pengelolaan ekowisata Sesaot yang berkelanjutan.

$$
\text { Untuk menjawab persoalan }
$$
tersebut dengan program pengabdian kepada masyarakat tentang Peningkatan Kapasitas BUMDes dalam Business Plan bagi Pengelolaan Kawasan Ekowisata Hutan Berkelanjutan di Desa Sesaot Kecamatan Narmada Kabupaten Lombok Barat, telah dilaksanakan. dan memberikan manfaat bagi pengelola BUMDES dan stakeholders terkait dalam pengelolaan kawasan ekowisata Sesaot. Tujuan umum yang ingin dicapai dari program pengabdian pada masyarakat ini adalah meningkatkan pengetahuan dan pemahaman BUMDes dan stakeholders (utamanya pelaku usaha di kawasan ekowisata Sesaot) dalam Perencanaan Bisnis dan menfasilitasi penyusunan business plan BUMDes bagi pengembangan usaha berkelanjutan di Kawasan Eko Wisata Desa Sesaot 
Kecamatan Narmada Kabupaten Lombok Barat.

\section{METODE KEGIATAN}

Pelaksanaan kegiatan pengabdian pada masyarakat ini dilakukan dengan menggunakan metode pendidikan orang dewasa dengan metode partisipatif melalui penyampaian materi dan menfasilitasi penyusunan business plan kepada pengelola BUMDes serta stakeholders lainnya yaitu pihak-pihak lain yang terkait dengan pengembangan kawasan ekowisata hutan di desa Sesaot kecamatan Narmada Kabupaten Lombok Barat.

Penyuluhan dan fasilitasi serta diskusi terarah telah dilakukan untuk menyerap data dan informasi tentang ragam dan perkembangan usaha yang ada serta masalah-masalah yang dihadapi dalam mengembangkan usaha, untuk menjadi dasar penyusunan dan penyempurnaan draft business plan. Kegiatan ini melibatkan 31 orang partisipan yang terdiri dari pengelola BUMDes serta pelaku usaha lain, serta instransi/lembaga lain yang terlibat dalam pengelolaan kawasan ekowisata serta petani pesanggem yang ikut memanfaatkan kawasan hutan sekitar. Perlaksanaan kegiatan merlalui tahaptahap persiapan, koordinasi dengan BUMDes dan pihak-pihak terkait di lapangan, sosialisasi dan penyuluhan dan diskusi terarah serta fasilitasi penyusunan business plan, dan evaluasi kegiatan.

Kegiatan pengabdian ini telah dilaksanakan di Aula Pertemuan Kawasan Wisata Sesaot di desa Sesaot Kecamatan Narmada Kabupaten Lombok Barat khususnya BUMDes serta Stakeholders yang terlibat dalam pengembangan kehutanan berkelanjutan di kawasan Sesaot yang berbatasan langsung dengan Kawasan Gunung Rinjani serta masyarakatnya mempunyai interaksi langsung dengan kawasan hutan dalam membangun penghidupan mereka. Wilayah ini juga memiliki potensi yang bagus untuk pengembangan ekowisata hutan serta usaha-usaha ekonomi yang terkait sehingga mempunyai potensi yang besar sebagai sumber penghidupan bagi masyarakat di wilayah tersebut jika dikelola secara berkelanjutan.

\section{HASIL DAN PEMBAHASAN}

Kegiatan program pengabdian pada masyarakat yang didanai oleh dana PNBP tahun 2018 ini telah dilaksanakan dengan tahap-tahap sebagai berikut. Pertama adalah Sosialisasi dan koordinasi dengan kelompok sasaran, yang dilaksanakan pada Hari Sabtu, 8 September 2018 bertemu dengan Sekretaris BUMDES membicarakan tentang rencana penyuluhan dan fasilitasi tentang penyusunan Business Plan yang tidak hanya kepada pengelola BUMDes tetapi juga dengan semua pihak yang terkait dengan pengelolaan kawasan wisata Sesaot.

Pada pertemuan tersebut berhasil diidentifikasi pihak dan kelompok yang diundang dan dilibatkan dalam penyuluhan dan fasilitasi, termasuk jumlah undangan dan akomodasi yang disediakan oleh TIM untuk pelaksanaan kegiatan pengabdian pada masyarakat. Selanjutnya dilakukan Kunjungan kedua yang dilaksanakan pada satu minggu kemudiaan, yaitu Sabtu, 17 September 2018 melakukan diskusi intensif dengan Pengurus BUMDes Desa Sesaot, yaitu Ketua dan Sekretaris di Kediaman 
Sekretaris BUMDEs mendiskusikan tentang seluk beluk terkait dengan organisasi dan usaha yang dikelola oleh BUMDes yang digunakan sebagai bahan untuk penyusunan Business Plan, kemudian berkunjung ke kawasan Wisata Sesaot untuk melakukan observasi lapangan serta melanjutkan diskusi tentang prospek pengembangan kawasan sesaot ke depan.

Kegiatan berikutnya adalah pelaksanaan penyuluhan dan fasilitasi penyusunan Business Plan dengan menggunakan metode pendidikan orang dewasa melalui teknik diskusi dan tukar menukar pendapat dan pandangan secara partisipatif dan terarah. Peserta kegiatan tidak hanya diikuti oleh pengurus atau pengelola BUMDes, yang menjadi target utama tetapi juga stakeholders terkait terutama pihak-pihak yang ikut bekerja dan terlibat dalam pengelolaan kawasan wisata Sesao seperti pemerintah desa, pelaku dan pengelola usaha di kawasan, petani pesanggem, pemuda, sehat pihakpihak terkait lainnya. Pelaksanaan kegiatan dilakukan selama sehari yaitu pada Hari Sabtu, 22 September 2018 bertempat di Aula Pertemuan Kawasan Wisata Sesaot, Desa Sesaot, Kecamatan Narmada, Kabupaten Lombok Barat, yang diikuti oleh 31 orang partisipan. Dalam pelaksanaannya, selain koordinasi dengan pihak kantor desa dan pengelola BUMDes, Tim juga dibantu oleh dua petugas administrasi yaitu dua mahasiswi alumni Fakultas Pertanian Universitas Mataram yang pernah melakukan penelitian di kawasan Wisata Sesaot.

Materi utama yang diberikan dalam penyuluhan dan fasilitasi adalah menyangkut teknik penyusunan business plan yaitu (1) pengertian dan pentingnya rencana bisnis; (2) Ciri-ciri rencana bisnis yang baik; (3) Hal-hal yang mendasar dalam rencana bisnis; (4) Bagian Utama dari Rencana Bisnis; (5) Komponen Rencana Bisnis; (6) Merumuskan Ringkasan eksekutif; (7) mengidentifikasi visi, misi, produk/jasa yang dikembangkan; (8) Strategi Pemasaran; (9)Analisis Persaingan; (10) Rencana Desain dan Pengembangan, (11) Rencana Operasional dan manajemen; dan (12) analisis rencana keuangan.

Penyuluhan dan fasilitasi dilakukan dengan pertama-tama memberikan materi teknik penyusunan rencana bisnis (business plan) melalui presentasi powerpoint dengan menggunakan LCD , selanjutnya dilakukan dengan diskusi terarah tentang materi yang disampaikan. Selain itu, forum digunakan untuk mengidentifikasi potensi dan permasalahan yang dihadapi dalam pengelolaan kawasan ekowisata. Peserta memberikan masukan dan saran-saran yang konstruktif. Pada akhir kegiatan dilakukan evaluasi dengan mengamati antusiasme dan manfaat yang dirasakan oleh peserta dari pemaparan yang sudah disampaikan. Selain itu, forum juga berhasil menggali potensi dan kegiatan usaha yang ada di kawasan serta masalah-masalah yang dihadapi, serta hal-hal yang ingin dikembangkan ke depan. Data dan informasi yang diperoleh dikombinasikan dengan data observasi lapangan dan hasil kajian terdahulu digunakan sebagai bahan dalam menfasilitasi penyusunan sehingga menghasilkan draft Business Plan BUMDes bagi pengembangan ekowisata ke depan. Selain hasil kegiatan ini akan menjadi laporan kegiatan dan artikel ilmiah yang mendiskusikan hasil pelaksanaan kegiatan ini.

Poin-poin penting yang dapat digali serta konfirmasi peserta tentang data dan 
informasi dari kajian literatur, wawancara, serta observasi lapangan di kawasan ekowisata yang menjadi acuan dalam penyusunan business plan adalah sebagai berikut: 1) Lembaga yang terlibat dalam kawasan sangat beragam: Badan Pengelola Badan Wisata, BUMDes: Tiketing dan Taman Miring; Koperasi Serba Usaha Sugih Engger: Desa Wisata Hijau (al. "Forest tracking", dan homestay), POKDARWIS, Local Working Groups (LWG). Masing-masing lembaga ini memiliki tugas dan kegiatan masingmasing dan diinisiasi oleh dinas/instansi pemerintah dan lembaga yang berbeda sehingga perlu ada koordinasi yang baik dalam pengelolaan ekowisata Sesaot, 2) Legalitas (pengurus) BUMDes masih belum ada dan bekerja belum optimal masih ditangani langsung oleh Desa.

Walaupun pengurus inti sdh dibentuk tetapi Desa belum mengeluarkan SK Pembentukan resmi dengan alas an belum terbentuknya unit-unit usaha yang berada di bawahnya, 3) Usaha-Usaha yang sudah dikembangkan dalam dan sekitar kawasan, yaitu Jasa perparkiran, Jasa masuk kompleks kolam renang, Pedagang Sate Bulayak, Pedagang Oleh-Oleh, Pemandu wisata (guide), Homestay, Penyewaan Ban Renang, Penyewaan Tikar Forest tracking, 4) Pengelolaan obyek wisata alam Sesaot oleh Badan Usaha Milik Desa (BUMDes) dengan pembagian hasil pengelolaan obyek wisata masingmasing sebesar $65 \%$ untuk pengelola obyek wisata melalui BUMDes, $10 \%$ untuk pendapatan desa, $10 \%$ untuk Pemerintah Kabupaten Lombok Barat dan $15 \%$ untuk Pemerintah Provinsi NTB, 5) Jasa utama yang dikelola BUMDesa adalah Jasa Perparkiran dan Tiket Masuk, di mana Tiket masuk: Rp. 5.000/ orang, Parkir Roda 2: Rp. 5.000,- Parkir Roda 4: Rp.
10.000,-. Selain itu ada jasa penyewaan di kompleks Kolam Renang, yaitu penyewaan tikar Rp. 5.000,-, penyewaan ban kecil Rp. 5.000, ban besan Rp. 10.000,- dan ban bermotif/berbentuk (floating) Rp. 10.000,per sekali pakai, 6) Kawasan memberikan kontribusi ekonomi yang memadai untuk masyarakat sekitar dari usaha yang dilakukan di kawasan, serta masalahmasalah lain yang perlu diperhatikan adalah sarana dan fasilitas yang ada belum optimal, pemasaran hasil agroindustri dari pengolahan hasil hutan yang masih terbatas, sistem ticketing yang masih manual dan belum menggunakan elektronik sehingga susah dikontrol jumlah pengunjung dan sebagainya.

Pada akhir acara setelah proses tukar pikiran secara terarah dan partisipatif, tim mengajukan beberapa pertanyaan sejauh mana materi-materi yang telah disampaikan dapat dimengerti dan dipahami oleh partisipan dan bermanfaat bagi peserta. Hasil evaluasi di akhir kegiatan menunjukkan bahwa sejak kehadiran peserta yang tepat waktu, penyampaian materi yang santai diselingi dengan permainan, serta dinamika yang berkembang dan data serta informasi yang tergali selama pertemuan maka bisa dikatakan bahwa penyuluhan dan fasilitasi ini adalah sangat berhasil.

Keberhasilan kegiatan didukung oleh kesesuaian topik yang dilakukan dengan kebutuhan BUMDes dan stakeholders di lokasi kegiatan yang belum mengembangkan rencana bisnis untuk usaha yang dijalankan. Bahan-bahan yang diberikan merupakan sesuatu yang relatif baru sehingga menarik perhatian peserta sehingga mendorong peserta untuk menggali data dan informasi serta memberikan saran-saran yang konstruktif 
dalam pengembangan kawasan ekowisata sesaot ke depan.

Sejak perencanaan, koordinasi, pelaksanaan penyuluhan termasuk fasilitasi penyusunan draft Business Plan BUMDes, serta evaluasi kegiatan berjalan dengan lancer dan baik menjadi respon yang cukup positif dari pengelola BUMDes, aparat desa, pelaku usaha di kawasan, kelompok dan lembaga yang terlibat dan ikut dalam pelaksanaan kegiatan tersebut. Peserta menyatakan bahwa materi yang disampaikan merupakan sesutau yang baru dan penting untuk ditindaklanjuti dalam perencanaan bisnis mereka. Dengan demikian, kegiatan ini dapat meningkatkan pengetahuan dan pemahaman BUMDes dan stakeholders (utamanya pelaku usaha di kawasan ekowisata Sesaot) dalam Perencanaan Bisnis.

Selain itu, Tim dapat meningkatkan kapasitas pengelola BUMDEs dalam penyusunan Business Plan bagi pengembangan usaha yang mandiri dan berkelanjutan dengan menfasilitasi penyusunan business plan sehingga menghasilkan draft Business Plan yang masih harus disempurnakan bagi pengembangan usaha ekowisata Sesaot ke depan. Selain itu, TIM menyelipkan materi pentingnya pembangunan kehutanan dan ekowisata yang berwawasan lingkungan yaitu mensinergikan antara fungsi social, ekonomi, dan pelestarian lingkungan dalam pemanfaatan dan pengelolaan kawasan ekowisata Sesaot.

Secara keseluruhan, kegiatan pengabdian pada masyarakat dalam kaitan dengan penyusunan business plan ini dinilai berhasil. Fenomena dan dinamika yang berkembang dalam proses kegiatan pengabdian ini mencerminkan adalah munculnya dan terungkapnya kemampuan dan kapasitas kognitif dan afektif dari pengelola BUMDes dan stakeholders terkait. Khusus bagi pengelola BUMDes, melalui kegiatan penyuluhan dan fasilitasi ini telah dihasilkan draft business plan. Apakah pemahaman dan peningkatan wawasan tentang penyusunan business plan dapat diwujudkan dalam perubahan perilaku (psikomotorik) dengan indicator ingin merumuskan business plan yang betulbetul untuk dioperasionalkan maka perlu pemantauan dan evaluasi lebih lanjut. Tim telah menyatakan kesediaan untuk dihubungi jika ada hal-hal yang didiskusikan dan difasilitasi dalam penyempurnaan business plan yang telah disusun.

Keberhasilan pelaksanaan kegiatan pengabdian pada masyarakat ini disebabkan oleh beberapa factor, yaitu: (1) Pemilihan topik sesuai dengan kebutuhan sasaran khususnya BUMDes serta stakeholders lainnya sehingga dari awal perencanaan sampai pelaksanaan kegiatan mendapat respon yang baik dan positif; (2) ada kesungguhan yang kuat dari peserta khususnya pengelola BUMDEs serta peserta lainnya untuk berusaha bagaimana meningkatkan kualitas pengelolaan dan hasil dan penerimaan yang diperoleh dari usaha ekonomi yang ditekuni yang ditunjukkan dengan kehadiran yang tepat waktu (bahkan jumlah peserta melebihi jumlah yang diundang), antusiasme dan keaktifan peserta dalam menyampaikan pertanyaan, pendapat, dan sumbangsih saran dalam forum penyuluhan tersebut; (3) Adanya bantuan dan kerja sama yang baik antara Tim pengabdian dengan Pengelola BUMDes Desa Sesaot yang menyediakan waktu dan tenaga untuk sosialisasi dan menyebarkan undangan, 
mengurus sarana dan fasilitas pertemuan serta pengadaan akomodasi pertemuan sehingga pertemuan berjalan secara kondusif dan lancar.

Meskipun rangkaian kegiatan dari mulai perencanaan sampai pelaksanaan kegiatan serta fasilitasi penyusunan draft business plan BUMDes berjalan dengan lancer dan baik, tetapi terdapat masalahmasalah yang dijumpai di lapangan. Salah satunya adalah status kepala desa Sesaot sekarang adalah dalam situasi non-aktif atau vakum (diemban oleh $\mathrm{Plt}$ ) sehingga pengambilan keputusan tentang keberlanjutan pengelolaan Ekowisata oleh BUMDes masih butuh waktu karena belum ada legalisasi. Selanjutnya, karena perbedaan latar belakang dari peserta yang berbeda baik dalam pendidikan maupun pengalaman sehingga tidak semua peserta bisa aktif dan berpartisipasi dalam forum, tetapi kehadiran mereka tentu tetaop bermanfaat dalam menambah pengetahuan dan wawasan mereka dalam penyusunan rencana bisnis.

\section{KESIMPULAN DAN SARAN}

\section{Kesimpulan}

Pelaksanaan Kegiatan pengabdian pada masyarakat berjalan dengan baik dan lancar sesuai dengan rencana dan target yang telah ditetapkan. Kegiatan pengabdian pada masyarakat ini dapat meningkatkan aspek kognitif dan afektif dari peserta khususnya pengelola BUMDes yang berkaitan dengan penyusunan rencana bisnis, serta pentingngnya pengelolaan kawan kehutanan dan ekowisata yang berwawasan lingkungan. Kegiatan pengabdian ini telah menjadi wahana desiminasi hasil penelitian di universitas Mataram kepada masyarakat pengguna untuk dimanfaatkan bagi kesejahteraan ekonomi masyarakat, sehingga terjalin hubungan yang dinamis dan saling mengisi antara perguruan tinggi dan masyarakat, pihak-pihak terkait lainnya.

\section{Saran}

Berdasarkan hasil pelaksanaan kegiatan maka diberikan beberapa saran sebagai berikut: Pengelola BUMDes dapat memanfaatkan pengetahuan dan ketrampilan yang diperoleh untuk penyempurnaan draft business plan yang telah difasilitasi. Kepada pengelola usaha dikawasan ekoswisata dapat juga memanfaatkan pengetahuan dan ketrampilan penyusunan business plan ini untuk pengembangan usaha mereka lebih lanjut. Proses pembelajaran adalah proses jangka panjang dan berkesinambungan, sehingga kegiatan pengabdian masyarakat seperti ini harus terus dilaksanakan agar kemanfaatan nya menjadi nyata.

\section{UCAPAN TERIMA KASIH}

Ucapan terima kasih disampaikan kepada Lembaga Penelitian dan Pengabdian kepada Masyarakat Universitas Mataram

\section{DAFTAR PUSTAKA}

Aji, Gutomo Bayu; Rusida Yuliyanti, Joko Suryanto, Andini Desita Ekaputra Tanjung Saptono, Hasriani Muis, 2015. Sumbangan Hutan Kemasyarakatan dan Hutan Desa terhadap Pendapatan dan Pengurangan Kemiskinan: Studi Kasus. Kerjasama penelitian antara: Pusat Penelitian Kependudukan LIPI dengan Kemitraan. The Partnership for Governance Reform. Jakarta.

Ashley, Caroline and Diana Carney, 1999. Sustainable livelihoods: Lessons from 
early experience. DFID: Department for International Development, London

Cahyono, Eko, 2012. Konflik Kawasan Konservasi dan Kemiskinan Struktural. Jurnal Politika Vol. 8 No. 1 Tahun 2012, Politik Sumberdaya Alam.

Departemen Kehutanan, 2009. Pangan dari Hutan (Kontribusi Sektor Kehutanan Dalam Mendukung Ketahanan Pangan Nasional), Makalah pada Seminar Seminar Nasional dalam rangka "Hari Pangan Sedunia, 12 Oktober 2009", Jakarta, 1 Otober 2009. http://www.dephut.go.id/ uploads/files/DEPHUT_Makalah_HPS. pdf.

Ellis, Frank, 1998). Household strategies and rural livelihood diversification. The Journal of Development Studies. Volume 35, Issue 1, 1998 P: 1-38

Garedew, Efrem, Mats Sandewall, UIf Soderberg, 2012. A Dynamic Simulation Model of Land-Use, Population, and Rural Livelihoods in the Central Rift Valley of Ethiopia, Environmental Management (2012) 49:151-162

Hasan, Rubangi Al ; Yumantoko, 2016. Kemiskinan Masyarakat Sekitar Hutan (Studi Kasus di Pulau Lombok). Balai Penelitian Teknologi Hasil Hutan Bukan Kayu: Lingsar, Lombok Barat, NTB.

http://www.pustaka.ut.ac.id/dev25/p dfprosiding2/fisip201224.pdf. Diakses 17 Maret 2016

Menteri Kehutanan Republik Indonesia, 2011. Peraturan Menteri kehutanan Republik Indonesia. No. 16/MenhutII/2011 Tentang Pedoman Umum Program nasional Pemberdayaan Masyarakat Mandiri Kehutanan.
Ngugi, Robinson K. And Dickson M. Nyariki, 2005. Rural livelihoods in the arid and semi-arid environments of Kenya: Sustainable alternatives and challenges. Agriculture and Human Values (2005) 22: 65-71

PSPK UGM, 2016. Ironi Relasi Hutan dan Masyarakat Desa. http://pspk.ugm. ac.id/seminar/107-ironi-hubungankehutanan-dengan-masyarakatdesa.html diakses 17 Maret 2016.

Qodriyatun, Sri Nurhayati, 2013. Pengentasan Kemiskinan Masyarakat Sekitar Hutan Konservasi: Studi Pemberdayaan Masyarakat Melalui Model Desa Konservasi Diterbitkan oleh: P3DI Setjen DPR Republik Indonesia dan Azza Grafika 2013. http://berkas.dpr.go.id/pengkajian/fil es/buku_individu/buku-individu-7.pdf Rangkuti, Freddy, 2000. Business Plan: Teknik Membuat Perencanaan Bisnis dan Analisis Kasus. Jakarta: PT Gramedia Pustaka Utama. 532 hal.

Rositah, Erna, 2005. Kemiskinan Masyarakat Desa Sekitar Hutan dan Penanggulangannya Studi Kasus di Kabupaten Malinau dalam Governance Brief: Forests and Governance Programme. Center for International Forestry Research. Agustus 2005 nomor 14 http://www.cifor.org/publications/pd f_files/govbrief/GovBrief0602.pdf

Start2grow (2015), BUSINESS PLAN MANUAL. Dapat diunduh dari www.start2grow.de

Walker, John (2009) Start-up Sample Business Plan. Continental Business Plan Consulting, LLC. New York, NY. Bisa diunduh dari http://www.spmvv.ac.in/ecell/docs/b usiness-models/3.pdf 
Wollenberg, Eva; Brian Belcher, Douglas Sheil, Sonya Dewi, Moira Moeliono, 2004. Mengapa kawasan hutan penting bagi penanggulangan kemiskinan di Indonesia? Governance Brief: Forests and Governance Programme. Desember 2004 Nomor 4 (i). Center for International Forestry Research.

http://www.cifor.org/publications/pd f_files/govbrief/GovBrief0404I.pdf

World Bank, 2006. Pertumbuhan Ekonomi, Penghidupan Pedesaan, dan Manfaat Lingkungan: Opsi-opsi Strategis untuk Bantuan Kehutanan di Indonesia, Jakarta: Bank Dunia.

WWF,2002. Penilaian Ekonomi

Sumberdaya Kawasan Rinjani. WWF, Mataram, NTB

WWF, 2012. Studi Model dan Mekanisme Pengelolaan Jasa Lingkungan di Kabupaten Lombok Tengah. Mataram, NTB.

Yakin, Addinul, 2000. Implikasi Sosial Ekonomi Pembangunan Hutan Kemasyarakatan dan Prospek Pengelolaan HPH melalui Koperasi: Kasus di Kabupaten Bima dan Dompu. Majalah Ilmiah Agriteksos Vol. 9(4), Januari 2000.

Yakin, Addinul, 2002. The Impact of Development of Rinjani Mountain National Park toward the Farmer's Economy in the Surrounding Area: A case study at the Village of Senaru, District of West Lombok. Majalah Ilmiah Agroteksos, Vol. 12 (2), Oktober 2002.

Yakin, Addinul dan Jamal Othman, 2003. "Forest Resource and Policy at the Age of Regional Autonomy in Indonesia", Paper yang dipresentasikan pada the 2-day International Seminar on "Sustainable Economic, Business, and Social Development in an Era of Globalization", 13/10/200314/10/2003 at Equatorial Hotel, Bangi, Selangor, Malaysia.

Yakin, Addinul, 2005. Community Involvement and Environmental Management of Rinjani National Park, Lombok Island in Mitsuda and Sayuti (editors), Sustainable Lombok: The Rich Nature and Rich People in the 21st Century. Mataram: Universitas Mataram Press: 93-120.

Yakin, Addinul, 2006. Implementation and Enforcement of Environmental Policies in Promoting Sustainable Development in Asia: Learning from Malaysia and Japan in Power, Purpose, Process, and Practice in Asia: The Work of API Fellows 2003/2004. Asian Public Intellectuals Program. Kuala Lumpur, Malaysia: Sasyaz Holdings Sdn. Bhd. Pages: 1-18.

Yakin, Addinul, 2006. Kebijakan Pengelolaan Sumber daya Hutan dan Tata Pamong Lingkungan di Era Otonomi Daerah. Paper yang disampaikan pada Seminar Nasional tentang Kehutanan yang diselenggarakan di Hotel Jayakarta, Lombok: 9-11 Juni 2006.

Yakin, Addinul dan Basrun, 2007. Valuasi Ekonomi Obyek Wisata Alam Joben di Taman Nasional Gunung Rinjani: Penerapan Metode Biaya Perjalanan. Jurnal Lemlit Unram, Volume Pebruari 2007

Yakin, Addinul dan Prasetyo, Gatut Gagah, 2009. Nilai Ekonomi Wisata Pendakian pada Kawasan Taman Nasional Gunung Rinjani di Pulau Lombok. 
Jurnal Lemlit Unram, Volume Pebruari 2009.

Yakin, Addinul, 2009. Analisis Sumberdaya Alam dan Pembangunan Ekonomi Berkelanjutan Propinsi NTB. Paper disampaikan pada Semiloka LECE SUEZ oleh WWW Nusa Tenggara dan Pemda Tk. I NTB, Hotel Lombok Raya 21 Juli 2009.

Yakin, Addinul, 2011. Prospek dan Tantangan Implementasi Pasar Karbon bagi Pengurangan Emisi Deforestasi dan Degradasi Hutan di Kawasan ASEAN. Paper disampaikan pada Seminar Nasional "Optimalisasi Integrasi Menuju Komunitas ASEAN 2015", Kerjasama Ditjen Kerja Sama
ASEAN, Kemenlu RI dan Universitas Mataram di Grand Legi, Mataram, Sabtu 10 Desember 2011.

Yakin, Addinul, 2015. Ekonomi Sumber Daya Alam dan Lingkungan: Teori, Kebijakan, dan Aplikasi bagi Pembangunan Berkelanjutan. Edisi Baru Cetakan Pertama. Akademika Pressindo Jakarta.

Yakin, Addinul., dkk. 2016. Analisis Strategi Penghidupan dan Kesejahteraan Ekonomi Rumahtangga Sekitar HutanBagi Pengembangan Kehutanan Berkelanjutan: Studi Kasus di Kecamatan Batukliang Utara, Lombok Tengah. Laporan Penelitian PNBP Universitas Mataram. 